\title{
Diabetic Foot Ulcers: Where Do We Currently Stand
}

\author{
Firas Kawtharani* \\ Instructor Fellow in Orthopaedic trauma Surgery, USA \\ *Corresponding author: Firas Kawtharani, Instructor Fellow in Orthopaedic trauma Surgery, USA
}

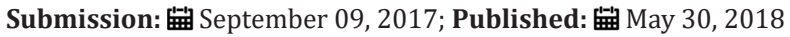

\begin{abstract}
Diabetic foot disease is a major burden on the healthcare system (10) with astronomical economic as well as social implications affecting patients especially when this entity leads to lower extremity amputations. This review attempts to identify the problem and its burden on the healthcare system and presents the latest evidence in finding a strategic plan to overcome this modern plague that is complicating the care of diabetic patients and is costing millions of tax payers' money.
\end{abstract}

\section{Mini Review}

Lower extremity amputations are common in western societies and the United States. More than 3,00,000 patients with amputations live in the US and 65,000 procedures are performed annually. Foot ulcers and mainly diabetes induced ones are responsible for $85 \%$ of lower extremity amputations. The reasons of their development are mainly neuropathy, angiopathy and intractable infections [1]. The longevity and quality of life of amputees is severely affected due to decreased mobility and increased oxygen consumption [2]. Indeed only $63 \%$ of major amputees recover independent ambulation using prosthesis [1]. In addition, Cultural factors including the patient background and ethnicity affects the management of these wounds and may lead to premature amputations [3]. The emergence of gram-negativespecies, which necessitate radical surgical treatment of osteomyelitis, is complicating the problem as well [4].

Several modalities of treatment are in practice to treat diabetic foot ulcers but the safest approach is prevention. The combination of strict diabetic control, frequent checkups, foot hygiene, adequate nutrition and aggressive wound care [5] all lead to control the rate of below knee amputations. State of the art wound care products and techniques including the use of colloid matrix, silver and biologics such as PDGF are contributing to advances in treatment of diabetic foot ulcers [6]. Goie [7] stress on the importance of education in avoiding the development of diabetic foot ulcer. Therefore using all potential resources such as translators, social workers and if need be psychiatric evaluation may help optimizing patient outcome.

An algorithm for approaching diabetic foot ulcers relying mainly on a multidisciplinary approach is needed [8]. It starts with adequate control of risk factors such as peripheral neuropathy, peripheral vascular disease, Smoking, trauma, duration of diabetes mellitus and high levels of HBA1C [9]. Awareness through education and close follow up [7] helps volumes. Proper diagnostic skills follow with a clear history, physical exam using relatively objective parameters such as the Wagner staging of ulcers.

Patients are then worked up with laboratory tests (inflammatory markers), and a neurological and vascular evaluation. A plan of care can thus be formulated addressing this prominent condition before it deteriorates $[8,10]$. In adopting a multidisciplinary approach, a team including podiatry, wound care nursing, infectious disease specialist and plastic and/or orthopedic surgeons participate in shared decision making regarding the treatment of diabetic ulcer patients [8]. State of the art modalities in wound management include various topical dressings (silver, colloids, wound vac etc.) as well as hyperbaric therapy and proper antibiosis. These factors contribute in concert to a dramatic change in the prognosis of the patient. Hospitals should create committees formed from administrators as well as physicians and nurses to monitor the results of the multidisciplinary approach aimed at treating diabetic foot ulcers. Problems that might be facing hospitals are lack of sufficient resources in equipment and personnel. Another challenge is the absolute cooperation and compliance of patients with following up with various healths care providers. An obligatory parameter needed to overcome these challenges is thorough education that will reassure the patient that the proposed plan of care will improve his/her prognosis [7]. The multidisciplinary team should meet on a regular basis to oversee the course of treatment of the diabetic foot ulcer patients. Concrete indicators and patient outcome parameters are necessary in making sure that progress is actually happening $[11,12]$. 


\section{References}

1. Damme VH, Rorive M, Noorthout BMM, Quaniers J, Scheen A, et al. (2006) Amputations in diabetic patients: a plea for foots paring surgery. Acta Chir Belg 101(3): 123-129.

2. Miyajima S, Shirai A, Yamamoto S, Okada N, Matsushita T (2009) Risk factors for major limb amputations in diabetic foot gangrene patients. Diabetes Res Clin Pract 71(3): 272-279.

3. Hjelm K, Apelqvist J (2016) Influence of beliefs about health and illness on self-care and care-seeking in foreign-born people with diabetic foot ulcers: dissimilarities related to origin. J Wound Care 25(11): 602-616.

4. Senneville E, Robineau O (2017) Treatment options for diabetic foot osteomyelitis. Expert Opin Pharmacother 18(8): 759-765.

5. Fearon J (1985) Improved results with diabetic below-knee amputations. Arch Surg 120(7): 777-780.

6. Health Quality Ontario (2016) Management of chronic pressure ulcers: an evidence-based analysis. Ont Health Technol Assess Ser 9(3): 1-203.
7. Goie TT, Naidoo M (2016) Awareness of diabetic foot disease amongst patients with type 2 diabetes mellitus attending the chronic outpatients department at a regional hospital in Durban, South Africa. Afr J Prim Health Care Fam Med 8(1): e1-e8.

8. Gupta SK, Singh SK (2012) Diabetic foot: a continuing challenge. Adv Exp Med Biol 771: 123-138.

9. Nongmaithem M, Bawa AP, Pithwa AK, Bhatia SK, Singh G, et al. (2016) Study of risk factors and foot care behavior among diabetics. J Family Med Prim Care 5(2): 399-403.

10. Tabur S, Eren MA, Çelik Y, Dağ OF, Sabuncu T, et al. (2015) The major predictors of amputation and length of stay in diabetic patients with acute foot ulceration. Wien Klin Wochenschr 127(1-2): 45-50.

11. Hanley M, Bhimji S (2017) Hyperbaric, Diabetic Foot Ulcer. Stat Pearls, Treasure Island (FL): Stat Pearls Publishing.

12. Kallio M, Vikatmaa P, Kantonen I, Lepäntalo M, Venermo M, et al. (2015) Strategies for free flap transfer and revascularisation with 10 year outcome in the treatment of large diabetic foot lesions. European Journal of vascular and endovascular surgery 50(2): 223-230.

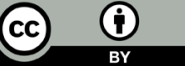

Creative Commons Attribution 4.0 International License

For possible submissions Click Here

\section{Submit Article}

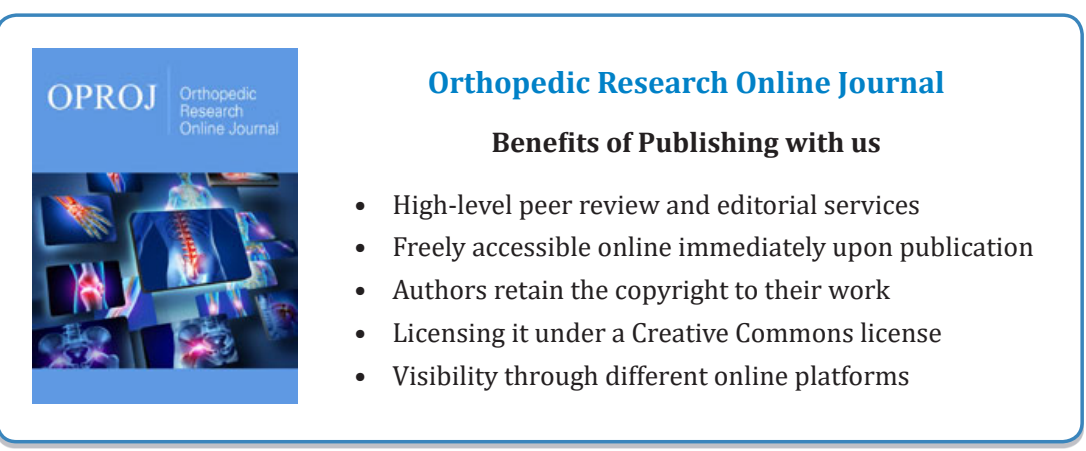

